\title{
HIV/AIDS stigma-associated attitudes in a rural Ethiopian community: characteristics, correlation with HIV knowledge and other factors, and implications for community intervention
}

Alan R Lifson ${ }^{1 *}$, Workneh Demissie², Alemayehu Tadesse ${ }^{2}$, Kassu Ketema $^{3}$, Randy May ${ }^{2}$, Bereket Yakob², Meka Metekia ${ }^{4}$, Lucy Slater ${ }^{5}$ and Tibebe Shenie ${ }^{2}$

\begin{abstract}
Background: Whether scale-up of HIV prevention and care will reduce negative attitudes and discriminatory practices towards persons living with HIV/AIDS (PLWH) is uncertain. An HIV knowledge and attitude survey was conducted in a rural Ethiopian community where HIV prevention and treatment was being rapidly scaled up. Data were analyzed to identify prevalence of and factors associated with stigma-associated attitudes towards PLWH.

Methods: We surveyed 561 adults from 250 randomly selected households in the rural town of Arba Minch and surrounding villages about positive or negative attitudes towards PLWH, as well as demographic characteristics, and knowledge about HIV transmission and treatment.

Results: Eighty percent of respondents agreed with $\geq 1$ negative statements indicating blame or shame towards PLWH and $41 \%$ agreed with $\geq 1$ negative statements associated with distancing themselves from PLWH. However, only $14 \%$ expressed negative responses about whether PLWH should receive support from their communities. In multivariate analysis, a greater number of negative attitudes towards PLWH was significantly $(p<0.05)$ associated with: female gender (Odds Ratio $[O R]=1.51$ ), living in a rural village (vs. town neighborhood) $(O R=3.44)$, not knowing PLWH can appear healthy $(O R=1.78)$, lack of knowledge about perinatal transmission $(O R=1.49)$, lack of knowledge about how HIV is not transmitted (e.g. casual contact) $(\mathrm{OR}=2.05)$, lack of knowledge about HIV treatment $(\mathrm{OR}=1.80)$, and not personally knowing a PLWH $(\mathrm{OR}=1.41)$.

Conclusions: In a rural Ethiopian setting in which rapid scale-up of HIV treatment occurred, many respondents still characterized HIV as associated with shame or blame, or indicated PLWH would be isolated or discriminated against. HIV stigma can hamper both prevention and treatment programs. We identified multiple issues which, if addressed, can help promote a more positive cycle in which PLWH are appreciated as members of one's own community who are affirmatively interacted with and supported. Stigma reduction programs should address knowledge gaps such as fears of casual contact contagion, and lack of awareness of medical interventions to help prevent HIV disease, as well as building upon community-based attitudes of the importance of supporting and showing compassion for PLWH.
\end{abstract}

\footnotetext{
* Correspondence: lifso001@umn.edu

'Division of Epidemiology and Community Health, University of Minnesota,

1300 S. Second Street, Suite 300, Minneapolis, MN 55454-1015, USA

Full list of author information is available at the end of the article
} 


\section{Background}

Despite international progress in scaling up HIV prevention and treatment efforts, negative attitudes and discriminatory practices towards persons living with HIV/AIDS (PLWH) represent a major and persistent barrier [1-17]. Stigma can occur at the community level, in institutions (e.g., healthcare facilities), and among PLWH themselves (internalized stigma). At the community level, stigma may include negative judgments about PLWH (e.g., blame or shame) and distancing (enacted stigma) practices, such as exclusion from social events or abandonment. For PLWH, fear of stigma and discrimination may be major barriers towards: seeking HIV testing to learn one's status, participation in prevention of mother to child transmission (MTCT), programs, disclosure of HIV status to spouses or others, linkage to and retention in HIV treatment, and adherence to antiretroviral therapy (ART) [1-15].

HIV stigma has been reported from many countries of sub-Saharan Africa (SSA) [1,3,6,8-12,14-18], where there are over 22 million PLWH, and where in 2009 alone there were 1.8 million new HIV infections and 1.3 million HIV deaths [19]. It has been suggested that in an era in which ART and other HIV care is becoming increasingly accessible, and HIV becomes viewed as a manageable disease, stigma and discrimination may reduce $[5,6,8,16,20]$. However, studies evaluating countries in SSA where ART has been scaled up have reached varying conclusions about the impact on HIV stigma $[6,16,18]$.

Ethiopia, with an estimated 1.1 million PLWH [21] reflects these challenges for SSA. A survey in Ethiopia and other East African countries during 2001-2003 (before ART became available) reported significant stigma at the community level, with contributing factors including an incomplete knowledge about HIV transmission (especially fear of casual contact), shame and blame associated with HIV as sexually transmitted, and fear of death [15]. In 2005, Ethiopia launched a program to provide free ART, with decentralization and rapid scale-up of HIV care; in 2009, ART was provided to an estimated 53\% of those with advanced HIV infection [21]. Education efforts include improving the percentage of the population who correctly understand ways of preventing HIV and reject major misconceptions about HIV transmission. The government has also been working closely with civil society to monitor stigma and discrimination towards PLWH, and to design programs to raise awareness and understanding.

Approximately $82 \%$ of Ethiopians live in rural areas [22], and available data suggested that HIV prevalence may be increasing in small market towns compared to large cities, with these smaller towns serving as bridging sites for urban to rural spread of HIV [21]. Other countries in SSA also face the challenge of rural HIV; more than two-thirds of the population in the 25 African countries most-affected by AIDS lives in rural areas [23].
Compared to those in urban areas, rural populations may have lower HIV knowledge and awareness levels, more difficulty accessing HIV testing and care, and greater challenges adhering to HIV treatment [23-27].

In preparation for a community support program for PLWH in rural southern Ethiopia, we conducted in 2010 a general population survey of HIV knowledge and attitudes towards PLWH; the study was conducted in an area in which HIV care and treatment activities were being rapidly scaled up. We determined the prevalence of negative attitudes towards PLWH, the level of knowledge about HIV transmission and treatment, and the correlation of negative attitudes with demographic characteristics and specific knowledge areas.

\section{Methods}

Study setting

Arba Minch is a rural town located in the foothills of the Rift Valley wall in southern Ethiopia. In addition to the town, many live in the surrounding villages and support themselves through farming. As of February 2010, 2,886 patients were enrolled in HIV care at Arba Minch Hospital, the main zonal referral hospital, and 1,849 had been started on ART, more than double the numbers from 2007; during the same three years, the number of HIV patients enrolled in care at the Arba Minch Health Clinic (a local clinic serving primarily the town) increased over eight-fold [28,29].

The smallest and one of the most important units of administration in Ethiopia is the kebele, based in a village or neighborhood; kebeles are responsible for many basic municipal services. Every resident of Ethiopia belongs to a kebele, and it is a strong focus of identification. Ten kebeles were selected from Arba Minch town and the surrounding villages for this survey: four kebeles were neighborhoods within Arba Minch town and six kebeles were in outlying villages. The main criterion for selection was prior knowledge that there were a large number of PLWH in that kebele; this was based on summary data on residence for patients enrolled in Arba Minch Hospital's HIV Clinic, plus information from local PLWH associations.

\section{Identification of sample households and participant recruitment}

Kebele administrations maintain a listing of all households, identified by family name; the mean number of households per kebele was 532 in the four town kebeles, and 704 in village kebeles. Using this list, for each kebele, 25 households were selected using a random number generator.

Interviewers approached each selected household and explained the study, indicating they would like to privately interview all adults living in that household. Inclusion criteria included age $\geq 18$ years and being a permanent resident of that kebele. The decision to interview all household 
adults was made so that in addition to the "head of the household", we would also get adequate representation of women and younger adults. To reach all adults, interviewers sometimes had to visit households on several occasions, including evenings or early mornings. If all adults in a household refused to be interviewed, or if the household could not be located, another household from the same kebele was randomly selected.

Of 250 households selected in the first randomization, in $34(14 \%)$ the family moved or otherwise could not be located (21\% in town neighborhoods and $9 \%$ in villages); 34 additional households were then chosen. Of 638 adult residents of these households who met inclusion criteria, 47 (7\%) had temporarily moved away (such as for school or work) or were otherwise unavailable; of the remaining $591,95 \%$ agreed to be interviewed. In only four households did all adults refuse participation.

Data collection occurred in 2010 by 24 graduate students or graduates of Arba Minch University, after a two-day pre-survey training. Surveys were conducted privately and administered verbally in Amharic. Survey items included: (a) demographic characteristics (e.g., age, gender, education, marital status); (b) positive and negative attitudes towards PLWH; and (c) knowledge about HIV transmission and HIV treatment.

Attitude and knowledge items were chosen after reviewing a number of published reports and validated questionnaires, and selected to reflect certain parameters of particular interest. Questions about attitudes towards PLWH were selected from three categories: (1) negative attitudes of blame or shame towards PLWH; (2) negative discrimination or exclusion practices towards PLWH; or (3) positive feelings of compassion towards PLWH and responsibility to support them. Questions on HIV knowledge were from five categories: (1) whether one could have HIV and appear healthy; (2) sexual HIV transmission and its prevention; (3) MTCT and its prevention; (4) how HIV is not transmitted (especially through casual contact); and (5) knowledge and benefits of HIV treatment, especially ART. Within each knowledge category, we evaluated the number of correct responses.

\section{Analysis}

We created an overall stigma score, assigning one point for each agreement with a negative attitude statement, and one point for each disagreement with a positive attitude statement. Respondents were dichotomized based upon the median stigma score. Univariate analyses with chi-square for categorical variables and Student's $t$-test for continuous variables were conducted to identify factors associated with an increased number of negative attitudes towards PLWH. Multivariate analysis was conducted using a generalized linear model with the GENMOD procedure in SAS [30], controlling for kebele of residence (since respondents within a kebele may be more similar than between kebeles).

\section{Ethics}

This study was reviewed and approved by the Institutional Review Boards of the University of Hawassa and the University of Minnesota. All study subjects provided informed consent, and data collectors were trained in informed consent procedures; household members who could not provide consent because of physical or mental illness were excluded. The project was also presented to kebele leaders, and permission was sought to work in the kebele.

\section{Results}

\section{Study population}

Of 561 participants, $65 \%$ were from rural villages and $35 \%$ from town neighborhoods. Fifty-three percent were female; the median age was 30 years (interquartile range $[I Q R]=22,44$ years). Sixty-two percent were married and $32 \%$ single; the remainder were widowed or separated. The median number of adults and children living in a household was $5(\mathrm{IQR}=4,8)$. In terms of highest level of education, $49 \%$ either never attended school or attended some primary school but had not completed it.

\section{Negative attitudes towards PLWH}

Responses to individual questions about attitudes towards PLWH are summarized in Table 1. Eighty percent responded with one or more negative responses associated with blame or shame towards PLWH, the most common (74\%) being that HIV was God's punishment for bad behavior. Forty-one percent responded with one or more negative responses associated with distancing themselves from PLWH, the most common being that they would not buy vegetables in the market from a person with AIDS (27\%). On the other hand, only $14 \%$ expressed one or more negative responses about whether PLWH should receive support from their communities; $92 \%$ said the community should help socially support them. Finally, $60 \%$ said they personally knew someone with HIV/AIDS.

\section{Knowledge about HIV}

Responses to individual knowledge questions about HIV are summarized in Table 2. The percent correctly answering all questions in each category were as follows: $70 \%$ for questions about whether one could have HIV and appear healthy; $68 \%$ for questions about sexual transmission, $40 \%$ for questions about MTCT, $54 \%$ for questions on how HIV is not transmitted, and 38\% for questions about ART/HIV treatment.

Of note, although $91 \%$ believed having one faithful uninfected sex partner was protective, $23 \%$ either did not 
Table 1 Attitudes about people living with HIV/AIDS, community residents of kebeles, Arba Minch, Ethiopia

\begin{tabular}{|c|c|c|c|}
\hline Blame or Shame: & $\underline{\text { Yes }}$ & No & $\underline{\mathrm{DK}}$ \\
\hline HIV is a punishment from God for bad behavior & $74 \%$ & $22 \%$ & $4 \%$ \\
\hline People with HIV should be ashamed of themselves & $36 \%$ & $62 \%$ & $2 \%$ \\
\hline I would be ashamed to be seen in public with friend known to have AIDS & $29 \%$ & $71 \%$ & $1 \%$ \\
\hline \multicolumn{4}{|l|}{ Distancing: } \\
\hline I would not buy vegetables in the market from someone who had AIDS & $27 \%$ & $71 \%$ & $2 \%$ \\
\hline PLWH in our kebele would not be welcome in weddings or parties & $15 \%$ & $85 \%$ & $<1 \%$ \\
\hline PLWH in our kebele would probably be abandoned or sent away by their spouse or family & $18 \%$ & $81 \%$ & $1 \%$ \\
\hline \multicolumn{4}{|l|}{ Support for PLWH: } \\
\hline If PLWH in our kebele, community should help socially support them & $92 \%$ & $6 \%$ & $1 \%$ \\
\hline If PLWH in our kebele, community should share responsibility for their care and treatment & $87 \%$ & $10 \%$ & $3 \%$ \\
\hline PLWH deserve our compassion and support & $94 \%$ & $4 \%$ & $3 \%$ \\
\hline
\end{tabular}

Abbreviations: PLWH: Person living with HIV/AIDS; DK= Don't know.

know or did not believe that condoms correctly and consistently used could provide protection. Thirty percent did not know that HIV could be transmitted during pregnancy or delivery, and $45 \%$ were unaware there are ways to prevent perinatal transmission; among women, $33 \%$ and $51 \%$ did not respond correctly to these questions. Reflecting some uncertainty about treatment for HIV, although $86 \%$ of respondents agreed there are treatments that could prolong the life of PLWH, 26\% believed that there was nothing someone with AIDS could do to help keep them alive and 23\% believed there was a "cure" for AIDS; in response to an open-ended follow-up question, some of the most common "cures" included "prayer", "faith" and "holy water". When asked if they felt they had enough information about HIV/ AIDS, 54\% responded "no".

Table 2 Knowledge about HIV transmission and treatment, community residents of kebeles, Arba Minch, Ethiopia

\begin{tabular}{|c|c|c|c|}
\hline HIV Infection vs. Disease: & Yes & No & $\underline{\mathrm{DK}}$ \\
\hline A healthy looking person can have HIV & $80 \%$ & $14 \%$ & $6 \%$ \\
\hline Only people who look sick can spread HIV & $15 \%$ & $82 \%$ & $3 \%$ \\
\hline \multicolumn{4}{|l|}{ Sexual Transmission: } \\
\hline Can get HIV by having sex with an infected person & $95 \%$ & $3 \%$ & $2 \%$ \\
\hline Can protect against HIV by having one uninfected faithful sex partner & $91 \%$ & $8 \%$ & $1 \%$ \\
\hline Can protect against HIV by using a condom correctly and consistently & $77 \%$ & $11 \%$ & $12 \%$ \\
\hline \multicolumn{4}{|l|}{ Mother-to Child Transmission: } \\
\hline A woman with HIV can give HIV to baby during pregnancy or delivery & $70 \%$ & $20 \%$ & $10 \%$ \\
\hline A woman with HIV can give HIV to her baby by breast feeding & $84 \%$ & $9 \%$ & $7 \%$ \\
\hline There are ways a pregnant woman with HIV can reduce the chance of giving HIV to her unborn child & $55 \%$ & $20 \%$ & $25 \%$ \\
\hline \multicolumn{4}{|l|}{ Ways HIV is Not Spread: } \\
\hline Can get HIV from mosquito bites & $26 \%$ & $66 \%$ & $8 \%$ \\
\hline Can get HIV by sharing a meal with PLWH & $11 \%$ & $88 \%$ & $2 \%$ \\
\hline Can get HIV by touching PLWH & $7 \%$ & $91 \%$ & $2 \%$ \\
\hline Can get HIV by sleeping in same room as PLWH & $10 \%$ & $87 \%$ & $3 \%$ \\
\hline My child could get HIV by playing with another child who had AIDS & $12 \%$ & $86 \%$ & $1 \%$ \\
\hline \multicolumn{4}{|l|}{ HIV Treatment: } \\
\hline If you get AIDS, there is nothing you can do to help keep you alive & $26 \%$ & $68 \%$ & $6 \%$ \\
\hline There are treatments that prolong the life of PLWH & $86 \%$ & $7 \%$ & $7 \%$ \\
\hline There is a cure for AIDS & $23 \%$ & $72 \%$ & $5 \%$ \\
\hline If PLWH gets started on ART, OK to stop once you feel better & $12 \%$ & $80 \%$ & $8 \%$ \\
\hline If PLWH gets started on ART, it is important to take every day to prevent them from becoming sick & $91 \%$ & $3 \%$ & $6 \%$ \\
\hline
\end{tabular}

Abbreviations: PLWH: Person living with HIV/AIDS; ART = antiretroviral therapy; DK= Don't know. 


\section{Determinants of negative attitudes towards PLWH}

On the nine attitude questions, 80 (14\%) expressed no negative responses, 278 (50\%) 1-2 negatives, 133 (24\%) $3-4$ negatives, and $70(12 \%) \geq 5$ negatives $($ median $=2)$. When evaluated as continuous variables, there was a high negative correlation between the number of negative attitudes expressed and the number of correct responses on the 18 knowledge questions $(\mathrm{r}=-0.465, \mathrm{p}<0.001)$.

Variables tested for their association with a higher stigma score (defined as $\geq 3$ negative responses) are summarized in Table 3. In univariate analysis, a higher stigma score was significantly $(\mathrm{p}<0.05)$ associated with the following characteristics: female gender, lower education level, and living in a village (vs. town) kebele. Age group was not associated with stigma; when evaluated as a continuous variable, the mean ages were 35.5 years for high stigma and 34.1 for lower stigma ( $p>0.10$ ). Higher stigma was significantly associated with giving one or more incorrect responses on the following knowledge areas: HIV infection vs. disease, sexual transmission, MTCT, ways HIV is not spread, and HIV treatment. Those who personally knew a PLWH were significantly less likely to have a high stigma score.

In a multivariate model which included all factors, seven were significantly $(\mathrm{p}<0.05)$ associated with a high stigma level: female gender, living in a rural village (vs. town neighborhood), not knowing PLWH can appear healthy, lack of knowledge about MTCT, belief in or uncertainty about ways HIV is not transmitted, lack of knowledge about HIV treatment, and not personally knowing a PLWH (Table 3); education level (whether or not at least completed primary school) and age group were of borderline significance.

\section{Discussion}

In a rural town and surrounding villages where HIV care and treatment is being rapidly scaled up, we found that components of HIV stigma are still common. Those who had more negative attitudes about PLWH were more likely to believe that HIV can be spread through casual contact or mosquitoes, and to lack knowledge about the natural history of HIV, as well as ART and its benefits. Personally knowing a PLWH was associated with fewer negative attitudes.

Health related stigma has been characterized as a process of social disqualification of individuals and populations identified with particular health problems, associated with exclusion, rejection, blame or devaluation [31]. Stigma can reflect and perpetuate existing inequalities and marginalization of socially disenfranchised groups [32].

Stigma was recognized early in the AIDS epidemic as a barrier to HIV prevention, treatment and support. Manifestations of HIV stigma include: negative judgments about PLWH (such as shame or blame-associated judgments); avoidance or discriminatory behaviors (enacted stigma) in family, community or institutional settings; discriminatory laws or policies; and self (internalized) stigma.

The focus of this analysis was HIV stigma in the community setting. Ethiopia, like many countries in SSA, is strongly grounded in the belief, especially in rural settings, that what happens to one person concerns the whole community; therefore, negative judgments and exclusion by the community can have devastating effects $[1,33]$.

In terms of attitudes towards PLWH, we found both positive and negative beliefs. On the one hand, $80 \%$ agreed with one or more negative judgments about PLWH that reflected shame or blame, and $41 \%$ agreed with actions reflecting distancing from PLWH. On the other hand, over $85 \%$ felt that PLWH deserved compassion and support from their communities. This seeming contradiction has been previously noted in Ethiopia and other African countries [15]. Even when PLWH are believed to have morally transgressed, a strong sense of community responsibility can lead people to believe that PLWH should still be cared for and treated with compassion [15,17].

Our finding of a significant correlation between HIV knowledge and negative attitudes towards PLWH is consistent with other studies linking poor knowledge about HIV/AIDS (including HIV transmission) with increased HIV stigma [2,3,34,35]. Knowledge gaps associated with stigma in our analysis included an incomplete understanding about how HIV is not transmitted (especially through casual contact), the natural history of HIV infection (which can initially be asymptomatic), ART (including its potential benefits), and MTCT (including prevention of perinatal transmission). It is concerning that $33 \%$ of women did not know that HIV could be transmitted perinatally, and that $51 \%$ were unaware that there are ways to reduce MTCT. In 2009, only $35 \%$ of all pregnant African women received an HIV test, and only $54 \%$ of HIV-positive women received ART to prevent MTCT [36].

Although knowledge about sexual transmission was not statistically associated with stigma, it is concerning that although over $90 \%$ knew that HIV could be transmitted sexually and that having one uninfected faithful partner was protective, $23 \%$ were uncertain or did not believe that people could protect themselves from HIV by consistent and correct condom use. Lack of awareness or belief in the benefits of condom use jeopardizes one important strategy in a comprehensive HIV prevention program $[37,38]$.

In our analysis, personally knowing a PLWH was a significant predictor of lower stigma. Other studies have also found that personal acquaintance with a PLWH is associated with less expressed stigma [6,35]. This supports the involvement of PLWH in both developing and implementing community-based stigma and discrimination-reduction efforts $[2,5,6]$, and the importance of PLWH being willing to disclose their status to others. 
Table 3 Multivariate analysis for demographic and knowledge factors associated with a high stigma score, community residents of kebeles, Arba Minch, Ethiopia

\begin{tabular}{|c|c|c|c|}
\hline \multirow[t]{2}{*}{ Characteristic } & \multirow{2}{*}{$\begin{array}{l}\text { Number (\%) with } \\
\text { High stigma score }^{*}\end{array}$} & \multicolumn{2}{|c|}{ Multivariate analysis } \\
\hline & & p-value & Odds ratio \\
\hline Gender & & 0.041 & \\
\hline Male & $72(28 \%)$ & & 1.00 (Referent) \\
\hline Female & $130(44 \%)$ & & $1.51(1.02,2.23)$ \\
\hline Age & & 0.081 & \\
\hline$\leq 21$ years & $46(38 \%)$ & & $0.57(0.32,1.01)$ \\
\hline $22-44$ years & $97(33 \%)$ & & $0.75 .(0.55 .1 .02)$ \\
\hline$\geq 45$ years & $58(42 \%)$ & & 1.00 (Referent) \\
\hline Education & & 0.051 & \\
\hline Completed primary school & $58(20 \%)$ & & 1.00 (Referent) \\
\hline Didn't complete primary school & $145(53 \%)$ & & $2.15(0.998,4.62)$ \\
\hline Residence & & $<0.001$ & \\
\hline Town neighborhood kebele & $36(18 \%)$ & & 1.00 (Referent) \\
\hline Rural village kebele & $167(46 \%)$ & & $3.44(2.16,5.50)$ \\
\hline Knowledge about infection vs. disease & & 0.042 & \\
\hline Correctly answers all items & $110(28 \%)$ & & 1.00 (Referent) \\
\hline Incorrect, one or more items & $93(56 \%)$ & & $1.78(1.02,3.08)$ \\
\hline Knowledge about sexual transmission & & $>0.10$ & \\
\hline Correctly answers all items & $111(29 \%)$ & & 1.00 (Referent) \\
\hline Incorrect, one or more items & $92(51 \%)$ & & $1.30(0.88,1.93)$ \\
\hline Knowledge about MTCT & & 0.014 & \\
\hline Correctly answers all items & $55(25 \%)$ & & 1.00 (Referent) \\
\hline Incorrect, one or more items & $148(44 \%)$ & & $1.49(1.09,2.06)$ \\
\hline Knowledge about ways HIV not spread & & $<0.001$ & \\
\hline Correctly answers all items & $65(22 \%)$ & & 1.00 (Referent) \\
\hline Incorrect, one or more items & $138(53 \%)$ & & $2.05(1.40,3.01)$ \\
\hline Knowledge about HIV treatment & & 0.046 & \\
\hline Correctly answers all items & $49(23 \%)$ & & 1.00 (Referent) \\
\hline Incorrect, one or more items & $154(45 \%)$ & & $1.80(1.01,3.21)$ \\
\hline Personally knows PLWH & & 0.020 & \\
\hline Yes & $88(27 \%)$ & & 1.00 (Referent) \\
\hline No & $108(50 \%)$ & & $1.41(1.06,1.89)$ \\
\hline
\end{tabular}

* defined as $\geq 3$ negative responses.

Abbreviations: PLWH: Person living with HIV/AIDS; ART = antiretroviral therapy.

Our findings of greater negative attitudes among those with lower education are consistent with other studies [35]. Our findings are also consistent with other studies in suggesting that stigma may manifest differently in men and women $[1,17,33]$. Finally, the presence of greater stigma among those living in rural villages is of particular note. Although rural HIV seroprevalence in Ethiopia is lower than in urban settings, over $80 \%$ of the Ethiopian population is rural; in 2007 , it was estimated that $38 \%$ of all PLWH were rural [39].

Although the focus of this analysis was on stigma in the community setting, stigma may occur in other settings such as health care facilities, may be reflected in laws and policies of governments and other institutions, may be internalized as well as external, and may overlap with additional stigma against marginalized groups such as sex workers or men who have sex with men. This supports the need to evaluate in each local setting how HIV stigma and discrimination are manifested, so that programs to combat it can be most effectively targeted.

There are several cautions in interpreting our results. Although interviewers were trained to ask questions in a nonjudgmental fashion, some participants may have given responses they considered socially desirable, rather than reflecting how they actually felt; if so, the degree of stigma may have been greater than we identified. Second, by 
design, this survey was conducted in kebeles with larger numbers of PLWH; communities with few or no HIVinfected residents may have had different responses. Third, survey responses will likely differ in other counties, as well as Ethiopian regions with a different cultural, religious or social make-up; results therefore cannot be directly generalized to all other sub-Saharan African rural communities. However, as described above, our finding concerning both the nature and determinants of stigma are consistent with studies from many other countries in SSA.

\section{Conclusions}

Knowing the prevalence and correlates of HIV-related stigma and discrimination represents an important and evidence-based component of "knowing your epidemic" to help guide HIV program efforts [2]. In a rural Ethiopian setting in which rapid scale-up of HIV treatment occurred, many respondents still characterized HIV as associated with shame or blame for bad behavior, or indicated that PLWH would be isolated or discriminated against.

Our results suggest that the best strategies to reduce such stigmatizing attitudes and practices at the community level towards PLWH will be multifaceted. Education programs need to address knowledge gaps such as fears of casual contact contagion, and lack of awareness of medical interventions to help prevent HIV disease. A variety of training techniques may be utilized, each being clear and appropriate for the target populations (including educational level, gender and cultural background), with opportunities to ask questions and engage in interactive discussion; the Ethiopian community conversations program is built on such a model [21].

Although necessary, providing such information about HIV may not be sufficient. Stigma reduction measures need to build upon the community-based attitudes identified in our survey of the importance of supporting and showing compassion for PLWH. This includes helping persons better understand stigmatizing attitudes and practices in their own community, and its harmful effects on PLWH. Religious and other opinion leaders, as well as PLWH, can play key role in such efforts.

The negative cycle of stigma prevents PLWH from learning and disclosing their status to their friends, family and community; our results indicate that lack of interaction with identified PLWH only furthers such stigma. We identified a number of issues which, if addressed, offer a changed path towards a positive cycle in which PLWH are recognized as members of one's own community who are affirmatively interacted with and supported.

\section{Competing interests}

There are no competing interests.

\section{Authors' contributions}

AL was lead on planning and coordinating the data collection, conducting analysis, and drafting the manuscript. All co-authors were involved in developing various aspects of the study protocol, including procedures for participant recruitment, as well as development of the questionnaire. WD, AT, RM, BY, MM and TT participated in implementation of this study, including training and supervision of data collectors, and communication with the kebeles in which this study took place. All coauthors provided feedback and recommendation on the interpretation of data collected in this study, Coauthors also offered valuable input and suggestions on draft versions of this manuscript, and all authors approve the final manuscript.

\section{Acknowledgements}

Funding for this project was provided by the World Health Organization's Country Office for Ethiopia, with additional assistance from the University of Minnesota's Office for International Programs. We wish to thank the following individuals and organizations who provided technical advice, support, or assistance on this study: Dr. Akram Eltom and staff of the HIV/ AIDS team from the World Health Organization's Country Office for Ethiopia; Ato Kare Chawecha, Head of the Regional Health Bureau, and all management committee members of Regional Health Bureau, Southern Nations, Nationalities, and People's Regional State; management committee members of Gamo Gofa Zonal Department; management committee members of Arba Minch Hospital; the Arba Minch zuria woreda health office; the Arba Minch town health office; the Arba Minch Health Center; Dr.

Solomon Zewdie from Johns Hopkins University/TSAlHAY; and Gezie Aba from the Ethiopian Office of the National Alliance for State and Territorial AIDS Directors. We also wish to acknowledge and thank all data collectors and data collection supervisors for their strong commitment and conscientious efforts in conducting these community surveys. We thank Rose Hilk for her invaluable assistance with programming and data management, and Alex Baker and Nick Meza for data entry. Finally, we wish to thank and extend our appreciation to the Arba Minch zuria woreda and Arba Minch town community at large for their important and generous participation as a study population.

\section{Author details}

${ }^{1}$ Division of Epidemiology and Community Health, University of Minnesota, 1300 S. Second Street, Suite 300, Minneapolis, MN 55454-1015, USA. 2Ethiopian Office, National Alliance of State and Territorial AIDS Directors, Addis Ababa, Ethiopia. ${ }^{3}$ World Health Organization Country Office for Ethiopia, Addis Ababa, Ethiopia. ${ }^{4}$ Regional Health Bureau, Southern Nations, Nationalities and People's Region, Hawassa, Ethiopia. ${ }^{5} \mathrm{Global}$ Program, National Alliance of State and Territorial AIDS Directors, Washington, DC, USA.

Received: 16 October 2011 Accepted: 9 March 2012 Published: 3 May 2012

\section{References}

1. Mbonu NC, van den Borne B, De Vries NK: Stigma of people with HIV/AIDS in sub-Saharan Africa: a literature review. J Trop Med 2009, 2009:145891.

2. UNAIDS: Reducing HIV stigma and discrimination: a critical part of national AIDS programmes. Geneva: Joint United Nations Programme on HIV/AIDS; 2007 [http://data.unaids.org/pub/Report/2008/JC1521_stigmatisation_en.pdf]

3. Ogden J, Nyblade L: Common at its core; HIV-related stigma across contexts. Washington, DC: International Center for Research on Women; 2005 [http://www.icrw.org/files/publications/Common-at-its-Core-HIV-RelatedStigma-Across-Contexts.pdf]

4. Obermeyer CM, Bott S, Carrieri P, et al: HIV testing, treatment and prevention: generic tools for operational research. Geneva: World Health Organization; 2009 [http://www.who.int/hiv/pub/operational/or_generic_tools.pdf]

5. Mahajan AP, Sayles JN, Patel VA, et al: Stigma in the HIV/AIDS epidemic: a review of the literature and recommendations for the way forward. AIDS 2008, 22(Suppl 2):67-79.

6. Pulerwitz J, Michaelis A, Weiss E, Brown L, Mahendra V: Reducing HIVrelated stigma: lessons learned from Horizons research and programs. Public Health Rep 2010, 125:272-281.

7. Nyblade L, MacQuarrie K: Can we measure HIV/AIDS-related stigma and discrimination? Current knowledge about quantifying stigma in developing countries. Washington, DC: United States Agency for International Development; 2006 [http://www.policyproject.com/pubs/generalreport/ Measure\%20HIV\%20Stigma.pdf]

8. Genberg BL, Hlavka Z, Konda KA, et al: A comparison of HIV/AIDS-related stigma in four countries: negative attitudes and perceived acts of 
discrimination towards people living with HIV/AIDS. Soc Sci Med 2009, 68:2279-2287.

9. Berendes S, Rimal RN: Addressing the slow uptake of HIV testing in Malawi: the role of stigma, self-efficacy, and knowledge in the Malawi BRIDGE project. J Assoc Nurses AIDS Care 2011, 22:215-228.

10. Sambisa W, Curtis S, Mishra V: AIDS stigma as an obstacle to uptake of HIV testing: evidence from a Zimbabwean national population-based survey. AIDS Care 2010, 22:170-186.

11. Kebaabetswe PM: Barriers to participation in the prevention of motherto-child HIV transmission program in Gaborone, Botswana a qualitative approach. AIDS Care 2007, 19:355-360.

12. Vu L, Andrinopoulos K, Mathews C, Chopra M, Kendall C, Eisele TP. Disclosure of HIV status to sex partners among HIV-infected men and women in Cape Town, South Africa. AIDS Behav 2012, 16:132-138.

13. Sayles JN, Wong MD, Kinsler JJ, Martins D, Cunningham WE: The association of stigma with self-reported access to medical care and antiretroviral therapy adherence in persons living with HIV/AIDS. J Gen Intern Med 2009, 24:1101-1108.

14. Assefa Y, Van Damme W, Mariam DH, Kloos H: Toward universal access to HIV counseling and testing and antiretroviral treatment in Ethiopia: looking beyond HIV testing and ART initiation. AIDS Patient Care STDS 2010, 24:521-525.

15. Nyblade L, Pande R, Mathur S, et al: Disentangling HIV and AIDS stigma in Ethiopia, Tanzania and Zambia. Washington, DC: International Center for Research on Women; 2003 [http://www.icrw.org/files/publications/ Disentagling-HIV-and-AIDS-Stigma-in-Ethiopia-Tanzania-and-Zambia.pdf]

16. Wolfe WR, Weiser SD, Leiter $K$, et al: The impact of universal access to antiretroviral therapy on HIV stigma in Botswana. Am J Public Health 2008, 98:1865-1871.

17. Ndinda C, Chimbwete C, McGrath N, Pool R, Mdp Group: Community attitudes towards individuals living with HIV in rural KwaZulu-Natal, South Africa. AIDS Care 2007, 19:92-101.

18. Roura M, Urassa M, Busza J, Mbata D, Wringe A, Zaba B: Scaling up stigma? The effects of antiretroviral roll-out on stigma and HIV testing. Early evidence from rural Tanzania. Sex Transm Infect 2009, 85:308-312.

19. UNAIDS: Global report: UNAIDS report on the global AIDS epidemic 2010. Geneva: Joint United Nations Programme on HIV/AIDS; 2010 [http://www. unaids.org/globalreport/documents/20101123_GlobalReport_full_en.pdf]

20. WHO, UNAIDS: Treating 3 million by 2005: making it happen: the WHO strategy. Geneva: World Health Organization, Joint United Nations Programme on HIV/AIDS; 2003 [http://www.who.int/3by5/publications/ documents/en/3by5StrategyMakingltHappen.pdf]

21. Federal HIV/AIDS Prevention and Control Office: Report on progress towards implementation of the UN Declaration of Commitment on HIV/AIDS. Addis Ababa: Federal Democratic Republic of Ethiopia; 2010 [http://www.unaids.org/ en/dataanalysis/monitoringcountryprogress/2010progressreportssubmittedby countries/ethiopia_2010_country_progress_report_en.pdf]

22. World Bank: Data: Rural population (\% of total population). [http://data. worldbank.org/indicator/SP.RUR.TOTL.ZS]

23. Food and Agricultural Organization of the United Nations: AIDS: A threat to rural Africa, fact sheet. [http://www.fao.org/FOCUS/E/aids/aids6-e.htm].

24. Peltzer K, Friend-du Preez N, Ramlagan S, Anderson J: Antiretroviral treatment adherence among HIV patients in KwaZulu-Natal, South Africa. BMC Public Health 2010, 10:111.

25. Peltzer K, Matseke G, Mzolo T, Majaja M: Determinants of knowledge of HIV status in South Africa: results from a population-based HIV survey. BMC Public Health 2009, 9:174.

26. Van Rompaey S, Kimfuta J, Kimbondo P, Monn C, Buve A: Operational assessment of access to ART in rural Africa: the example of Kisantu in Democratic Republic of the Congo. AIDS Care 2011, 23:686-693.

27. Wilson DP, Blower S: How far will we need to go to reach HIV-infected people in rural South Africa? BMC Med 2007, 5:16

28. Ethiopian Ministry of Health, Federal HIV/AIDS Prevention and Control Office: Update as of end of Tir 2002 (February, 2010). Monthly HIV Care and ART Update. [http://www.etharc.org/resources/download/finish/42/347]

29. Ethiopian Ministry of Health, Federal HIV/AIDS Prevention and Control Office: Monthly HIV Care and ART Update. Update as of end of Tir, 1999 (February 10, 2007). [http://www.etharc.org/resources/download/finish/42/220]

30. SAS Institute Inc: SAS/STAT 9.22 User's Guide. Cary, NC: SAS Institute Inc; 2010.

31. Weiss MG, Ramakrishna J, Somma D: Health-related stigma: rethinking concepts and interventions. Psychol Health Med 2006, 11:277-287.
32. Parker R, Aggleton P: HIV and AIDS-related stigma and discrimination: a conceptual framework and implications for action. Soc Sci Med 2003, 57:13-24.

33. Rankin WW, Brennan S, Schell E, Laviwa J, Rankin SH: The stigma of being HIV-positive in Africa. PLoS Med 2005, 2:e247.

34. Kalichman SC, Simbayi LC, Cain D, Jooste S, Skinner D, Cherry C: Generalizing a model of health behaviour change and AIDS stigma for use with sexually transmitted infection clinic patients in Cape Town, South Africa. AIDS Care 2006, 18:178-182.

35. Hamra M, Ross MW, Orrs M, D'Agostino A: Relationship between expressed HIV/AIDS-related stigma and HIV-beliefs/knowledge and behaviour in families of HIV infected children in Kenya. Trop Med Int Health 2006, 11:513-527.

36. WHO, UNAIDS, UNICEF: Towards universal access: Scaling up priority HIV/AIDS interventions in the health sector: Progress report 2010. Geneva: World Health Organization; 2010 [http://whqlibdoc.who.int/publications/2010/ 9789241500395_eng.pdf]

37. Kurth AE, Celum C, Baeten JM, Vermund SH, Wasserheit JN: Combination HIV prevention: significance, challenges, and opportunities. Curr HIV/AIDS Rep 2011, 8:62-72.

38. Kennedy CE, Medley AM, Sweat MD, O'Reilly KR: Behavioural interventions for HIV positive prevention in developing countries: a systematic review and meta-analysis. Bull World Health Organ 2010, 88:615-623.

39. Federal Ministry of Health, HIV/AIDS Prevention and Control Office: Single point HIV prevalence estimate, June 2007. [http://www.etharc.org/ aidsineth/publications/singlepointprev_2007.pdf]

doi:10.1186/1472-698X-12-6

Cite this article as: Lifson et al:: HIV/AIDS stigma-associated attitudes in a rural Ethiopian community: characteristics, correlation with HIV knowledge and other factors, and implications for community intervention. BMC International Health and Human Rights 2012 12:6.

\section{Submit your next manuscript to BioMed Central and take full advantage of:}

- Convenient online submission

- Thorough peer review

- No space constraints or color figure charges

- Immediate publication on acceptance

- Inclusion in PubMed, CAS, Scopus and Google Scholar

- Research which is freely available for redistribution

Submit your manuscript at www.biomedcentral.com/submit
C) Biomed Central 